\title{
Risk-Adjusted Outcome Analysis of Endovascular Abdominal Aortic Aneurysm Repair in a Large Population: How Do Stent-Grafts Compare?
}

\section{Corine J. van Marrewijk, MSc구 ${ }^{1}$ Lina J. Leurs, MSc ${ }^{1}$; Srinivasa R. Vallabhaneni, MD, FRCS ${ }^{2}$; Peter L. Harris, MD, FRCS ${ }^{2}$; Jacob Buth, MD¹; and Robert J.F. Laheij, PhD ${ }^{1}$ on behalf of the EUROSTAR collaborators}

1Department of Vascular Surgery, Catharina Hospital, Eindhoven, The Netherlands. ${ }^{2}$ Regional Vascular Unit, Royal Liverpool University Hospital, Liverpool, United Kingdom.

\begin{abstract}
$\checkmark$
Purpose: To compare differences in the applicability and incidence of postoperative adverse events among stent-grafts used for repair of infrarenal aortic aneurysms.

Methods: An analysis of 6787 patients from the EUROSTAR Registry database was conducted to compare aneurysm morphological features, patient characteristics, and postoperative events for the AneuRx, EVT/Ancure, Excluder, Stentor, Talent, and Zenith devices versus the Vanguard device (control) and each other. Annual incidence rates of complications were determined, and risks were compared using the Cox proportional hazards analysis.

Results: The annual incidence rates were: device-related endoleak (types I and III) 6\% (range $4 \%-10 \%$ ), type II endoleak 5\% (range 0.3\%-11\%), migration 3\% (range 0.5\%-5\%), kinking $2 \%$ (range $1 \%-5 \%$ ), occlusion $3 \%$ (range $1 \%-5 \%$ ), rupture $0.5 \%$ (range $0 \%-1 \%$ ), and all-cause mortality 7\% (range 5\%-8\%). After adjustment for factors influencing outcome, AneuRx, Excluder, Talent, and Zenith devices were associated with a lower risk of migration, kinking, occlusion, and secondary intervention compared to the Vanguard device. Significant increased risk for conversion (EVT/Ancure) and reduced risk of aneurysm rupture (AneuRx and Zenith) and all-cause mortality (Excluder) were found compared to the Vanguard device.

Conclusions: Significant differences exist between stent-grafts of different labels in terms of applicability and complications during intermediate to long-term follow-up. Since each stent-graft has its drawbacks, no single label can be identified as the best. It is reassuring that developments in stent-grafts indeed result in better performance than the early stentgrafts. However, a single device incorporating all the perceived improvements should still be pursued.
\end{abstract}

J Endovasc Ther 2005;12:417-429

Key words: abdominal aortic aneurysm, endovascular repair, complications, adverse events, stent-graft failure, endoleak, mortality, rupture, outcome analysis

Endovascular repair of abdominal aortic aneurysm was introduced in the early 1990s as a minimal access alternative to conventional repair. The first stent-grafts implanted were homemade devices ${ }^{1,2}$ and served to establish the feasibility of the technique. These proto-

The authors have no commercial, proprietary, or financial interest in the products or companies described in this article.

Address for correspondence and reprints: C.J. van Marrewijk, De Klerklaan 49, 5624 BB Eindhoven, The Netherlands. Fax: 31-40-244-3370; E-mail: c.vanmarrewijk@mdl.umcn.nl 
types were followed by a range of commercially manufactured devices, which have been implanted in relatively large numbers of patients over the past decade. ${ }^{3-9}$

To be effective, a stent-graft needs to maintain fixation, hemodynamic seal, mechanical integrity, and patency over many years. However, a stent-graft implanted in an aortic aneurysm is subjected to several adverse factors that tend to compromise these functions. Several modes of stent-graft failure have been documented, and the lessons learned from early experiences led to changes in various features of many endografts and withdrawal of some early models. ${ }^{10}$

Stent-grafts provided by different manufacturers differ in their physical properties and design features. Each stent-graft system has its own characteristics, upon which the manufacturers claim specific advantages in terms of applicability and durability. However, no single device incorporating all the perceived improvements exists, which is at least in part due to patent/copyright protection of some of these design features.

Published comparisons of outcomes with different stent-graft models are confined to short and intermediate-term analyses or small series. ${ }^{11-16}$ Comparison of several stentgraft models in large numbers of patients over mid to long-term follow-up may provide insights into relative strengths of each device. The aim of this study was to compare different models of endografts in terms of preoperative anatomical variables of the aneurysm and postoperative outcomes. The EUROSTAR series is ideally suited for such a comparative assessment because of the range of stentgraft models included. Comparative analysis is indeed one of the prime purposes of a voluntary multicenter registry of this kind. ${ }^{17}$ This article provides an extensive amount of data to support detailed comparison among the stent-graft models.

\section{METHODS}

\section{EUROSTAR Project}

EUROSTAR (European Collaborators on Stent-graft Techniques for Abdominal Aortic Aneurysm Repair) project was launched in
1996 in response to the introduction of the new technique of repairing aortic aneurysms. The project was designed as a voluntary panEuropean multicenter registry to allow collection of as much data as possible in as short a time as possible for expeditious scientific evaluation of this technique. Registration is done on an "intention-to-treat" basis, and data are collected prospectively by means of case record forms (paper or online format). Preoperative evaluation, operative details, and follow-up data are collected. Follow-up protocol requires patient assessment by contrast-enhanced computed tomography (CT) at $1,3,6,12$, and 18 months after the operation and yearly thereafter. The surveillance protocol also includes annual plain radiography and clinical examination. The information is stored on an Oracle database (Oracle Corporation, Redwood Shores, CA, USA) for periodic analysis. Patients enrolled in the database received information about this registry and consented to have their data included in the study. ${ }^{18,19}$

This analysis covered patients who received a commercially made stent-graft between January 1994 and August 2004: AneuRx (Medtronic Vascular, Santa Rosa, CA, USA), EVT/Ancure (Guidant Indianapolis, IN, USA), Excluder (W.L. Gore \& Associates, Flagstaff, AZ, USA), Stentor (MinTec, La Ciotat, France), Talent (Medtronic Vascular), Vanguard (Boston Scientific, Natick, MA, USA), and Zenith (Cook, Indianapolis, IN, USA). The Stentor was regarded as a first-generation device, the Vanguard and EVT/Ancure as second-generation, and all other brands as thirdgeneration stent-grafts.

\section{Definitions of Outcome Events}

Endoleaks, kinking, migration, and occlusion of the stent-graft occurring after the first postoperative month were included as reported by individual investigators. It is expected that current recommended reporting standards are followed for definition and diagnosis, but the absence of a central core laboratory facility means that these complications are not verified.

Device-related (types I and III) and isolated type II endoleaks were analyzed as separate 
events. Aneurysm growth and shrinkage were regarded only when the maximum transverse aneurysm diameter changed at least $8 \mathrm{~mm}$ from the preoperative measurement. Secondary interventions included all reinterventions other than conversion to open repair, which was regarded as a separate event.

\section{Patient Sample}

During the observation period, 6787 patients $(6341$ men; mean age 72 years, range 28-100) from 181 hospitals (Appendix) in 19 countries were included in this analysis. The mean preoperative aneurysm diameter was $58 \mathrm{~mm}$ (range 30-145) and the mean duration of follow-up was 21 months (range 0-108). The distribution of stent-graft models over time is given in Table 1. Preoperative anatomical characteristics of the aneurysms and other baseline patient characteristics are presented for each stent-graft in Table 2.

\section{Statistical Analyses}

The primary aim of the analysis was to compare patients who were treated by the different stent-graft models. Preoperative anatomical details of the aneurysm were analyzed to identify differences in the applicability of different endograft models. Adverse events during follow-up were examined to characterize the performance of different models. In order to render this comparison quantitative, annual incidence rates $\left(\mathrm{IR}_{\mathrm{ann}}\right.$ : number of events/person-years at risk) for each complication were calculated for the entire cohort and for each stent-graft model.

Patients were grouped according to the endograft model. Comparisons performed using Cox proportional hazards modeling are reported as hazard ratios (HR) and 95\% confidence intervals. To allow direct comparison between two different stent-grafts models, risks of the different complications were calculated comparing each model of stent-graft against each other model. Thereafter, the risk quantification of complications was adjusted for differences in baseline characteristics because these factors could potentially influence the observed association. Adjustments were made in models with the group of pa- tients who received a Vanguard device as a control. In each consecutive model, one more group of the following factors were added to the prior model: (1) year of operation; (2) age at operation, gender, and smoking status; (3) "high risk" for operation and general anesthesia, a history of previous laparotomy, and obesity; (4) preoperative aneurysm morphological characteristics, including maximum diameter, aneurysm length, aortic neck angulation, neck diameter, etc.; and finally (5) stent-graft configuration and experience of the operating team. This stepwise modeling enabled determination of any influence of the individual or grouped baseline characteristics on the risk. Dummy variables were added to the models to account for missing values. Comparisons achieving $\mathrm{p}<0.05$ (2-tailed) were considered to be statistically significant. All statistical analyses were performed using SAS software (version 8.0; SAS Institute Inc., Cary, NC, USA)

\section{RESULTS}

\section{Endoleaks}

Device-related endoleaks were observed at $\geq 1$ month in $10 \%(n=673)$ of the 6787 patients, within an at-risk period of 10,868 person-years. Overall, the annual incidence rate was $6.2 \%$. It was highest ( $\left.\mathrm{IR}_{\mathrm{ann}}: 9.6 \%\right)$ in patients with a Stentor and lowest ( $\left(\mathrm{R}_{\mathrm{ann}}: 4.1 \%\right)$ in patients with a Zenith device (Table 3 ). Statistically significant differences in the risk of device-related endoleak (types I and III) were found for Zenith compared to any other stentgraft except Excluder and for AneuRx, Excluder, and Talent versus EVT/Ancure and Stentor (Table 4). Compared to Vanguard (Table 5), the risk of these endoleaks was reduced $35 \%$, $46 \%, 26 \%$, and $55 \%$ in patients with, respectively, an AneuRx (HR: 0.65, p<0.001), Excluder (HR: 0.54, $p<0.001$ ), Talent (HR: 0.74, $p=0.01$ ), or Zenith (HR: $0.45, p<0.001$ ) stentgrafts, while it was increased by 1.45 times in patients with a Stentor device $(p=0.003)$. However, after adjustment for baseline characteristics, statistical significance remained only for patients with an AneuRx (HR: 0.72, $p=0.02$ ) or a Zenith (HR: $0.49, p<0.001$ ) device compared to those with a Vanguard device. 


\begin{tabular}{|c|c|c|c|c|c|c|c|c|c|c|}
\hline & Annual N & mber o & Regi & $\begin{array}{l}\text { ABLE } \\
\text { tered }\end{array}$ & $\begin{array}{l}1 \\
\text { Stent-c }\end{array}$ & Araft In & nplant & tions & & \\
\hline & Totals & $\leq 1995$ & 1996 & 1997 & 1998 & 1999 & 2000 & 2001 & 2002 & $\geq 2003$ \\
\hline AneuRx & 999 (15\%) & - & 4 & 89 & 265 & 273 & 205 & 90 & 49 & 24 \\
\hline EVT/Ancure & $176(3 \%)$ & 11 & 10 & 41 & 30 & 34 & 16 & 6 & 23 & 5 \\
\hline Excluder & $808(12 \%)$ & - & - & - & 29 & 90 & 108 & 153 & 190 & 238 \\
\hline Stentor & $308(5 \%)$ & 165 & 143 & - & - & - & - & - & - & - \\
\hline Talent & 1579 (23\%) & - & 9 & 60 & 101 & 168 & 223 & 282 & 306 & 430 \\
\hline Vanguard & 929 (14\%) & - & 89 & 372 & 304 & 149 & 15 & - & - & - \\
\hline Zenith & $1988(29 \%)$ & - & - & - & 15 & 159 & 317 & 483 & 487 & 527 \\
\hline Totals & 6787 & 176 & 255 & 562 & 744 & 873 & 884 & 1014 & 1055 & 1224 \\
\hline
\end{tabular}

The association between Excluder $(p=0.05)$ and Vanguard $(p=0.07)$ was of borderline significance in the fully adjusted model.

Isolated type II endoleaks occurred in 8\% $(n=542)$ of patients within an at-risk period of 11,203 person-years. The annual incidence rate was $4.8 \%$ overall, ranging from $0.3 \%$ in patients with a Stentor to $10.5 \%$ in patients with an Excluder device (Table 3). The risk of isolated type II endoleak (Table 4) differed significantly for Excluder compared to any other label except EVT/Ancure, for Stentor versus any other label, and for Talent compared to Zenith. The risk was $88 \%$ lower in patients with a Stentor (HR: 0.12, $\mathrm{p}<0.001$ ), and 1.54 times increased in patients with an Excluder $(p=0.004)$ compared to Vanguard (Table 5). However, these associations were due to differences in baseline characteristics. Statistically significant reductions in isolated type II endoleaks appeared in patients with an AneuRx (HR: 0.71, $p=0.045$ ), a Talent (HR: $0.45, p<0.001$ ), or a Zenith (HR: $0.59, p=0.007$ ) device versus Vanguard after correction for year of operation and persisted in the fully adjusted model.

\section{Change in Aneurysm Diameter $\geq 8 \mathrm{~mm}$}

Aneurysm diameter increase occurred in $6 \%(n=378)$ of the patients within an at-risk period of 11,332 person-years. Overall, the annual incidence rate was $3.3 \%$, ranging from $2.2 \%$ in patients with an EVT/Ancure to $4.3 \%$ in patients with a Talent device (Table 3). Aneurysm growth was found to be statistically different only between patients with an AneuRx (HR: 0.68, $p=0.03$ ) stent-graft com- pared to patients with a Talent device (Table 4). This remained unchanged after adjusted analysis with Talent as control (data not shown). None of the stent-grafts differed from Vanguard regarding growth of the aneurysm (Table 5).

Shrinkage of the aneurysm diameter occurred in 5 times as many patients $130 \%$, $\mathrm{n}=2031$ ) within a much shorter at-risk period (8931 person-years). The overall annual incidence rate was $22.7 \%$. Shrinkage was observed most often ( $\left.I R_{a n n}: 35.0 \%\right)$ in patients with a Zenith and least often (IR $\left.\mathrm{ann}_{\mathrm{a}}: 6.6 \%\right)$ in patients with a Stentor device (Table 3). Statistically significant differences in the hazard ratio of shrinkage were found between almost all stent-graft labels except AneuRx and Excluder, both versus Vanguard and each other, and for Talent and Zenith compared to EVT/ Ancure (Table 4). In the unadjusted comparison to Vanguard (Table 5), the aneurysm shrank least often in patients with a Stentor (HR: 0.49, $p<0.001$ ) and more frequently in patients with EVT/Ancure (HR: 1.41, $p=0.008$ ), Talent (HR: 1.36, $p<0.001$ ), or Zenith (HR: 1.54, $\mathrm{p}<0.001)$ devices. After adjustment for baseline characteristics, the associations of EVT/ Ancure, Talent, and Zenith were unchanged.

\section{Migration}

Graft migration was observed in 5\% $(n=323)$ of the patients in an at-risk period of 11,459 person-years. The annual incidence rate, which was $2.8 \%$ overall, ranged from $0.5 \%$ in patients with an EVT/Ancure to $5.0 \%$ in patients with a Vanguard stent-graft (Table 3). Higher risk of graft migration was found 
TABLE 2

Percentage of Preoperative Characteristics per Stent-Graft Label

\begin{tabular}{|c|c|c|c|c|c|c|c|}
\hline & AneuRx & EVT/Ancure & Excluder & Stentor & Talent & Vanguard & Zenith \\
\hline $\begin{array}{l}\text { Mean follow-up, } m \\
\text { [range] }\end{array}$ & $24[0-72]$ & $29[0-96]$ & $14[0-60]$ & $51[0-108]$ & $16[0-84]$ & $36[0-96]$ & $15[0-72]$ \\
\hline \multicolumn{8}{|l|}{$\begin{array}{l}\text { Aortic neck } \\
\text { Diameter, mm }\end{array}$} \\
\hline $\begin{array}{l}<20 \\
20-24 \\
\geq 25\end{array}$ & $\begin{array}{c}6(59) \\
64(641) \\
20(200)\end{array}$ & $\begin{array}{l}13(22) \\
70(123) \\
13(23)\end{array}$ & $\begin{array}{c}6(49) \\
69(557) \\
22(175)\end{array}$ & $\begin{aligned} 7 & (22) \\
34 & (105) \\
7 & (22)\end{aligned}$ & $\begin{array}{c}4(60) \\
42(666) \\
49(770)\end{array}$ & $\begin{array}{l}13(124) \\
67(619) \\
16(149)\end{array}$ & $\begin{aligned} & (84) \\
47 & (940) \\
45 & (904)\end{aligned}$ \\
\hline \multicolumn{8}{|l|}{ Length, mm } \\
\hline $\begin{array}{l}\quad<16 \\
\quad 16-30 \\
>30 \\
\text { Angulation present }\end{array}$ & $\begin{array}{l}14(144) \\
53(526) \\
27(272) \\
19(194)\end{array}$ & $\begin{array}{r}9(15) \\
38(66) \\
20(36) \\
21(37)\end{array}$ & $\begin{array}{l}10(81) \\
55(446) \\
30(243) \\
27(216)\end{array}$ & $\begin{array}{l}8(24) \\
66(202) \\
19(59) \\
14(42)\end{array}$ & $\begin{array}{l}16(248) \\
53(834) \\
26(418) \\
21(329)\end{array}$ & $\begin{array}{c}8(78) \\
57(526) \\
29(273) \\
23(214)\end{array}$ & $\begin{array}{l}20(388) \\
51(1016) \\
25(502) \\
23(458)\end{array}$ \\
\hline \multicolumn{8}{|l|}{$\begin{array}{l}\text { Aneurysm } \\
\text { Diameter, mm }\end{array}$} \\
\hline $\begin{array}{l}\quad<50 \\
\quad 50-59 \\
\geq 60 \\
\text { Angulation present }\end{array}$ & $\begin{array}{c}23(225) \\
43(427) \\
32(318) \\
9(86)\end{array}$ & $\begin{array}{l}15(27) \\
47(83) \\
36(63) \\
11(20)\end{array}$ & $\begin{array}{l}20(160) \\
48(384) \\
31(248) \\
12(96)\end{array}$ & $\begin{aligned} 28 & (86) \\
39 & (121) \\
28 & (87) \\
3 & (8)\end{aligned}$ & $\begin{array}{l}12(189) \\
42(667) \\
43(684) \\
11(169)\end{array}$ & $\begin{array}{l}23(210) \\
44(406) \\
33(303) \\
12(114)\end{array}$ & $\begin{array}{l}13(252) \\
43(845) \\
43(849) \\
11(227)\end{array}$ \\
\hline \multicolumn{8}{|l|}{$\begin{array}{l}\text { Right iliac artery } \\
\text { Diameter, mm }\end{array}$} \\
\hline $\begin{array}{l}\quad<11 \\
\quad 11-15 \\
\geq 16 \\
\text { Angulation present }\end{array}$ & $\begin{array}{l}11(109) \\
45(445) \\
15(145) \\
28(277)\end{array}$ & $\begin{array}{r}20(36) \\
32(57) \\
6(10) \\
23(41)\end{array}$ & $\begin{array}{l}13(106) \\
33(270) \\
12(99) \\
33(270)\end{array}$ & $\begin{aligned} 28 & (85) \\
41 & (125) \\
6 & (18) \\
13 & (41)\end{aligned}$ & $\begin{aligned} 7 & (109) \\
31 & (495) \\
20 & (312) \\
32 & (501)\end{aligned}$ & $\begin{array}{l}32(297) \\
48(444) \\
12(111) \\
38(353)\end{array}$ & $\begin{array}{r}7(139) \\
23(459) \\
22(444) \\
33(661)\end{array}$ \\
\hline \multicolumn{8}{|l|}{$\begin{array}{l}\text { Left iliac artery } \\
\text { Diameter, mm }\end{array}$} \\
\hline $\begin{array}{l}\quad<11 \\
\quad 11-15 \\
\geq 16 \mathrm{~mm} \\
\text { Angulation present }\end{array}$ & $\begin{array}{l}13(131) \\
45(445) \\
11(113) \\
33(330)\end{array}$ & $\begin{aligned} 19 & (34) \\
32 & (56) \\
5 & (9) \\
29 & (51)\end{aligned}$ & $\begin{aligned} 15 & (121) \\
33 & (266) \\
9 & (71) \\
37 & (300)\end{aligned}$ & $\begin{aligned} 30 & (92) \\
38 & (118) \\
6 & (18) \\
15 & (46)\end{aligned}$ & $\begin{aligned} & 7(113) \\
& 33(521) \\
& 17(275) \\
& 37(582)\end{aligned}$ & $\begin{aligned} 33 & (309) \\
50 & (463) \\
8 & (78) \\
44 & (411)\end{aligned}$ & $\begin{aligned} 6 & (126) \\
27 & (533) \\
18 & (359) \\
39 & (767)\end{aligned}$ \\
\hline \multicolumn{8}{|l|}{ Aneurysm classification } \\
\hline $\begin{array}{l}\text { Aortic } \\
\text { Aortoiliac }\end{array}$ & $\begin{array}{l}62(615) \\
28(278)\end{array}$ & $\begin{array}{l}47(83) \\
12(21)\end{array}$ & $\begin{array}{l}75(606) \\
23(185)\end{array}$ & $\begin{array}{l}34(106) \\
23(70)\end{array}$ & $\begin{array}{l}65(1021) \\
32(513)\end{array}$ & $\begin{array}{l}69(644) \\
28(264)\end{array}$ & $\begin{array}{l}63(1253) \\
36(710)\end{array}$ \\
\hline \multicolumn{8}{|l|}{ Device configuration } \\
\hline $\begin{array}{l}\text { Bifurcated } \\
\text { Other }\end{array}$ & $\begin{array}{l}92(919) \\
8(80)\end{array}$ & $\begin{array}{l}70(124) \\
30(52)\end{array}$ & $\begin{array}{l}96(772) \\
4(36)\end{array}$ & $\begin{array}{l}90(276) \\
10(32)\end{array}$ & $\begin{array}{l}85(1344) \\
15(235)\end{array}$ & $\begin{array}{l}96(890) \\
4(39)\end{array}$ & $\begin{array}{l}89(1761) \\
11(227)\end{array}$ \\
\hline \multicolumn{8}{|c|}{ Hospital experience, number of procedures } \\
\hline $\begin{array}{l}<60 \\
\geq 60\end{array}$ & $\begin{array}{l}61(613) \\
39(386)\end{array}$ & $\begin{array}{l}70(123) \\
30(53)\end{array}$ & $\begin{array}{l}58(467) \\
42(341)\end{array}$ & $\begin{array}{l}78(239) \\
22(69)\end{array}$ & $\begin{array}{l}69(1093) \\
31(486)\end{array}$ & $\begin{array}{l}75(701) \\
25(228)\end{array}$ & $\begin{array}{l}47(932) \\
53(1056)\end{array}$ \\
\hline
\end{tabular}

Percentage of patients within the device group (number of patients) unless indicated otherwise.

between AneuRx and Vanguard devices compared to the other stent-grafts and between Stentor and Talent versus EVT/Ancure, Excluder, and Zenith (Tables 4 and 5 ). In the adjusted model compared to Vanguard (Table 5), the significance of the decreased risks of migration remained, except in patients with a Stentor or AneuRx device.

\section{Kinking}

Stent-graft kinking occurred in $4 \%(n=257)$ of the patients during an at-risk period of 11,387 person-years. Overall, the annual incidence rate of kinking was $2.3 \%$. It was highest $\left(\mathrm{IR}_{\mathrm{ann}}: 5.0 \%\right)$ for patients with a Vanguard and lowest $\left(I R_{a n n}: 0.6 \%\right)$ for patients with an Ex- 
TABLE 3

Annual Incidence Rates of Complications According to Stent-Graft Model

\begin{tabular}{|c|c|c|c|c|c|c|c|c|}
\hline & AneuRx & $\begin{array}{c}\text { EVT/ } \\
\text { Ancure }\end{array}$ & Excluder & Stentor & Talent & Vanguard & Zenith & Totals \\
\hline \multicolumn{9}{|l|}{ Device-related } \\
\hline \multicolumn{9}{|c|}{ 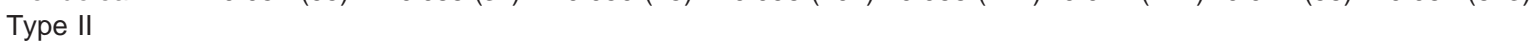 } \\
\hline endoleak & $0.045(84)$ & $0.050(19)$ & $0.105(89)$ & $0.003(4)$ & $0.046(90)$ & $0.037(95)$ & $0.070(161)$ & 0.048 (542) \\
\hline Growth & $0.027(50)$ & $0.022(9)$ & $0.042(37)$ & 0.027 (33) & $0.043(84)$ & 0.027 (72) & $0.040(93)$ & $0.033(378)$ \\
\hline Shrinkage & $0.203(311)$ & $0.264(74)$ & 0.209 (163) & $0.066(71)$ & $0.300(440)$ & $0.171(336)$ & $0.350(636)$ & 0.227 \\
\hline Migration & $0.043(81)$ & $0.005(2)$ & $0.011(10)$ & $0.031(38)$ & $0.024(48)$ & $0.050(128)$ & $0.007(16)$ & $0.028(323)$ \\
\hline Kinking & $0.011(21)$ & $0.022(9)$ & $0.006(6)$ & $0.039(46)$ & $0.010(20)$ & $0.050(125)$ & $0.012(30)$ & $0.023(257)$ \\
\hline Occlusion & 0.019 (37) & $0.033(13)$ & $0.011(10)$ & 0.037 (44) & $0.023(46)$ & $0.053(133)$ & $0.035(84)$ & $0.032(367)$ \\
\hline Conversion & $0.019(38)$ & $0.054(23)$ & $0.009(8)$ & $0.033(43)$ & $0.021(44)$ & $0.022(63)$ & $0.006(15)$ & $0.020(234)$ \\
\hline \multicolumn{9}{|l|}{ Secondary } \\
\hline intervention & $0.063(113)$ & $0.096(34)$ & $0.035(32)$ & $0.094(98)$ & $0.066(127)$ & $0.107(245)$ & 0.053 (122) & $0.073(771)$ \\
\hline Rupture & $0.004(7)$ & $0.000(0)$ & $0.001(1)$ & $0.008(11)$ & $0.005(10)$ & $0.008(23)$ & $0.002(4)$ & $0.005(56)$ \\
\hline Death & 0.067 (132) & $0.047(20)$ & $0.048(45)$ & $0.058(75)$ & $0.071(146)$ & $0.075(212)$ & $0.075(185)$ & $0.068(815)$ \\
\hline
\end{tabular}

Data presented as annual incidence rate (number of patients).

cluder stent-graft (Table 3). The risk of graft kinking differed significantly between thirdgeneration models (AneuRx, Excluder, Talent, and Zenith) compared to the early models (EVT/Ancure, Stentor, and Vanguard; Tables 4 and 5). The risk of kinking in any stent-graft but Stentor versus Vanguard (Table 5) remained significantly lower after adjustment for the differences in baseline characteristics (Table 5).

\section{Occlusion}

Stent-graft occlusion was also reported in $5 \%(n=367)$ of the patients, though in a shorter at-risk period (11,316 person-years). The overall annual incidence rate was 3.2\% (range $1.1 \%$ for Excluder to $5.3 \%$ for Vanguard; Table 3). The risk of graft (limb) occlusion was reduced in patients with an Excluder compared to any other stent-graft and in patients with an AneuRx or Talent compared to Zenith. All of these in turn had a lower risk of limb occlusion than Stentor or Vanguard (Tables 4 and 5). Significance of any of the associations compared to Vanguard (Table 5) remained after adjustments for baseline characteristics.

\section{Reinterventions}

Conversion to open repair was performed in $3 \%(n=234)$ of all patients. Of these, 76 con- versions were performed within 30 days of the initial operation. The annual incidence rate for conversion was $2.0 \%$ overall. It was highest in patients with an EVT/Ancure (5.4\%) and lowest for patients with a Zenith stentgraft $(0.6 \%$; Table 3$)$. Comparison of stentgrafts showed a significantly lower conversion risk in patients with an Excluder or Zenith compared to any other device and for AneuRx or Talent compared to EVT/Ancure and Stentor (Table 4). After adjustments, the risk of conversion to open repair was 2.32 times higher in patients with an EVT/Ancure $(p=0.02)$ and $62 \%$ lower in patients with a Zenith device $(p=0.008)$ compared to Vanguard (Table 5), but this risk was no longer significantly different between Vanguard and Excluder.

One or more secondary interventions were necessary in $11 \%(n=771)$ of the patients; these were transfemoral, transabdominal, and extra-anatomic, respectively, in 625, 59, and 162 patients. The annual incidence rate was $7.3 \%$ (range from $3.5 \%$ for Excluder to $10.7 \%$ for Vanguard; Table 3). The risk of these reinterventions was significantly reduced for Excluder compared to any other stent-graft, for Zenith versus any other brand except Excluder, and for AneuRx or Talent compared to the early devices (EVT, Stentor, and Vanguard; Table 4). The reduced risk of reintervention with a third-generation device (AneuRx, Ex- 
TABLE 5

Unadjusted and Adjusted Hazard Ratios of Outcome Events Compared to Vanguard Stent-Graft

\begin{tabular}{|c|c|c|c|c|c|c|}
\hline & \multicolumn{6}{|c|}{ Hazard Ratio (95\% Confidence Interval) } \\
\hline & AneuRx & EVT/Ancure & Excluder & Stentor & Talent & Zenith \\
\hline \multicolumn{7}{|c|}{ Type I/III endoleak } \\
\hline Unadjusted & $0.65(0.5-0.8)$ & $1.12(0.8-1.6)$ & $0.54(0.4-0.7)$ & $1.45(1.1-1.9)$ & $0.74(0.6-0.9)$ & $0.45(0.4-0.6)$ \\
\hline Adjusted & $0.72(0.5-1.0)$ & $1.21(0.7-2.0)$ & $0.67(0.4-1.0)^{\# 5}$ & $0.81(0.4-1.6)^{\# 1}$ & $0.75(0.5-1.0)^{\# 1}$ & $0.49(0.3-0.7)$ \\
\hline \multicolumn{7}{|c|}{ Type II endoleak } \\
\hline Unadjusted & $0.94(0.7-1.3)$ & $1.20(0.7-2.0)$ & $1.54(1.2-2.1)$ & $0.12(0.0-0.3)$ & $0.78(0.6-1.0)$ & $1.12(0.9-1.4)$ \\
\hline Adjusted & $0.71(0.5-1.0)^{\# 1}$ & $1.03(0.6-1.9)$ & $0.86(0.6-1.3)^{\# 1}$ & $0.40(0.1-2.3)^{\# 1}$ & $0.45(0.3-0.7)$ & $0.59(0.4-0.9)^{\# 1}$ \\
\hline \multicolumn{7}{|l|}{ Growth } \\
\hline Unadjusted & $0.88(0.6-1.3)$ & $0.78(0.4-1.6)$ & $1.20(0.8-1.8)$ & $1.03(0.7-1.6)$ & $1.30(0.9-1.8)$ & $1.19(0.9-1.6)$ \\
\hline Adjusted & $0.91(0.6-1.4)$ & $0.96(0.4-2.1)$ & $1.03(0.6-1.7)$ & $1.08(0.4-2.9)$ & $1.35(0.9-2.0)$ & $1.01(0.6-1.6)$ \\
\hline \multicolumn{7}{|l|}{ Shrinkage } \\
\hline Unadjusted & $1.02(0.9-1.2)$ & $1.41(1.1-1.8)$ & $0.93(0.8-1.1)$ & $0.49(0.4-0.6)$ & $1.36(1.2-1.6)$ & $1.54(1.3-1.8)$ \\
\hline Adjusted & $1.03(0.9-1.2)$ & $1.52(1.1-2.1)$ & $0.84(0.7-1.1)^{\# 1,4}$ & $0.78(0.5-1.3)^{\# 1}$ & $1.29(1.1-1.6)^{\# 1,3}$ & $1.42(1.2-1.7)$ \\
\hline \multicolumn{7}{|l|}{ Migration } \\
\hline Unadjusted & $0.91(0.7-1.2)$ & $0.10(0.0-0.4)$ & $0.25(0.1-0.5)$ & $0.60(0.4-0.9)$ & $0.53(0.4-0.7)$ & $0.15(0.1-0.2)$ \\
\hline Adjusted & $0.92(0.7-1.3)$ & $0.18(0.0-0.8)$ & $0.27(0.1-0.6)$ & $0.61(0.2-1.5)^{\# 1}$ & $0.47(0.3-0.7)$ & $0.13(0.1-0.2)$ \\
\hline \multicolumn{7}{|l|}{ Kinking } \\
\hline Unadjusted & $0.21(0.1-0.3)$ & $0.44(0.2-0.9)$ & $0.12(0.1-0.3)$ & $0.85(0.6-1.2)$ & $0.19(0.1-0.3)$ & $0.23(0.2-0.3)$ \\
\hline Adjusted & $0.25(0.1-0.4)$ & $0.34(0.1-0.9)$ & $0.17(0.1-0.4)$ & $0.86(0.4-2.0)$ & $0.25(0.1-0.4)$ & $0.36(0.2-0.7)$ \\
\hline \multicolumn{7}{|l|}{ Occlusion } \\
\hline Unadjusted & $0.32(0.2-0.5)$ & $0.59(0.3-1.0)$ & $0.14(0.1-0.3)$ & $0.78(0.6-1.1)$ & $0.33(0.2-0.5)$ & $0.49(0.4-0.6)$ \\
\hline Adjusted & $0.39(0.3-0.6)$ & $0.70(0.3-1.4)$ & $0.18(0.1-0.4)$ & $0.49(0.2-1.1)$ & $0.34(0.2-0.5)$ & $0.53(0.3-0.9)$ \\
\hline \multicolumn{7}{|l|}{ Conversion } \\
\hline Unadjusted & $0.83(0.6-1.2)$ & $2.34(1.5-3.8)$ & $0.32(0.2-0.7)$ & $1.47(1.0-2.2)$ & $0.81(0.5-1.2)$ & $0.23(0.1-0.4)$ \\
\hline Adjusted & $1.15(0.7-1.8)$ & $2.32(1.2-4.6)$ & $0.69(0.3-1.6)^{\# 1}$ & $0.59(0.3-1.3)$ & $1.08(0.7-1.8)$ & $0.38(0.2-0.8)$ \\
\hline \multicolumn{7}{|c|}{ Secondary intervention } \\
\hline Unadjusted & $0.54(0.4-0.7)$ & $0.86(0.6-1.2)$ & $0.26(0.2-0.4)$ & $0.96(0.8-1.2)$ & $0.51(0.4-0.6)$ & $0.40(0.3-0.5)$ \\
\hline Adjusted & $0.57(0.4-0.7)$ & $0.90(0.6-1.4)$ & $0.29(0.2-0.5)$ & $0.67(0.4-1.2)$ & $0.51(0.4-0.7)$ & $0.40(0.3-0.5)$ \\
\hline \multicolumn{7}{|l|}{ Rupture } \\
\hline Unadjusted & $0.50(0.2-1.2)$ & - & $0.17(0.0-1.3)$ & $0.91(0.4-1.9)$ & $0.72(0.3-1.5)$ & $0.26(0.1-0.8)$ \\
\hline Adjusted & $0.32(0.1-0.9)^{\# 4}$ & - & $0.13(0.0-1.2)$ & $0.34(0.0-2.7)$ & $0.44(0.2-1.2)$ & $0.10(0.0-0.4)$ \\
\hline \multicolumn{7}{|l|}{ Death } \\
\hline Unadjusted & $0.80(0.6-1.0)$ & $0.60(0.4-0.9)$ & $0.49(0.4-0.7)$ & $0.84(0.6-1.1)$ & $0.75(0.6-0.9)$ & $0.78(0.6-1.0)$ \\
\hline Adjusted & $0.94(0.7-1.2)^{\# 1}$ & $0.67(0.4-1.2)^{\# 1}$ & $0.62(0.4-0.9)$ & $0.73(0.4-1.4)$ & $0.79(0.6-1.0)^{\# 1}$ & $0.86(0.6-1.2)^{\# 1}$ \\
\hline
\end{tabular}

Statistically significant ratios appear in bold type.

Adjusted results include correction for 1: year of operation, 2: demographics, 3: clinical characteristics, 4: vascular morphology, and 5: stent-graft-related factors.

\# Correction level changing the significance of the association.

cluder, Talent, and Zenith) compared to Vanguard (Table 5) remained after adjustments for baseline characteristics.

\section{Rupture}

Rupture of the treated aneurysm was documented in $56(0.8 \%)$ of the 6787 patients within an at-risk period of 11,946 personyears, giving an overall annual incidence of rupture of $0.5 \%$. So far, no ruptures have been reported in patients with an EVT/Ancure device. The aneurysm rupture rate was highest $\left(\mathrm{IR}_{\mathrm{ann}}: 0.8 \%\right)$ in patients with a Stentor or Vanguard device (Table 3). Due to the small numbers of ruptures, statistically significant differ- 
ences were found only for Zenith compared to Stentor (HR: 0.28, $p=0.04$ ) and Vanguard (HR: 0.26, $p=0.01$; Tables 4 and 5). The association between Zenith and Vanguard persisted after adjustments. Additionally, a statistically significant reduced risk of rupture appeared for the AneuRx (HR: 0.32, $p=0.04$ ) device versus Vanguard (Table 5) after adjustment for vascular morphology.

\section{Mortality}

A total of 815 (12\%) patients died during an at-risk period of 11,953 person-years. One hundred and sixty-eight $(2.5 \%)$ patients died within 30 days, of which 15 underwent conversion to open repair. Of the 647 late deaths, $23(4 \%)$ followed a conversion. Overall, the (all-cause) annual mortality rate was $6.8 \%$ and was highest ( $\left.\mathrm{IR}_{\mathrm{ann}}: 7.5 \%\right)$ in patients with a Zenith and lowest ( $\left(R_{\mathrm{ann}}: 4.7 \%\right)$ in patients with an EVT/Ancure stent-graft (Table 3). The risk of (all-cause) mortality was statistically significantly lower for Excluder versus any other label except EVT/Ancure (Table 4). Compared to Vanguard (Table 5), mortality risk was decreased for all labels except Stentor. However, significantly reduced mortality compared to Vanguard remained only in patients with an Excluder (38\%) device after adjustment for baseline characteristics. The same was found when analyzing the combined risk of rupture and death or that of rupture, conversion, and death (data not shown).

\section{DISCUSSION}

Although there are several articles reporting long-term results of endovascular repair with individual makes of stent-grafts, ${ }^{7,9,19-25}$ only a few compared different endograft models. ${ }^{11-}$ 16,26 Based upon small numbers, these studies identified several factors that potentially influence outcome. Patient-related risk factors, such as age and comorbidities, mainly influence short-term results. ${ }^{19,27}$ Factors related to arterial morphology influence short-term success as well as long-term outcome. For example, adverse anatomical features, such as an unfavorable aneurysm neck or narrow iliac arteries, may lead to technical failure at the initial repair. Progressive changes in arterial anatomy during follow-up, such as neck dilatation or aneurysmal transformation of iliac landing zones, may compromise stent-graft function later on. 14,15,24,28-30 Physician-related factors, such as diagnostic insight, judgment of suitability for treatment, and operating experience, also influence outcome. ${ }^{31}$ All of these factors have been constantly changing as endovascular repair has evolved, creating a potential confounding effect upon comparative analyses. The present study hypothesized that (independent) differences exist between different makes of stent-grafts, which suggests that there are endograft-related factors that influence outcome. Therefore, the statistical methods included staged correction for these potentially confounding factors. The results support a conclusion that stent-graftrelated factors do significantly impact outcome independent of all the other factors.

Adjustment steps for demographic and clinical characteristics brought out only minor changes for the outcome events studied. On the other hand, correction for differences in year of operation or factors of vascular morphology resulted in considerable shifts in the risks of complications and in the significance of their associations. Occasionally this was profound, with a reversal of the direction of association. This study confirms the findings of others, as described above, and underlines the importance of risk adjustment in such analyses. Unadjusted risk estimations (e.g., Kaplan-Meier analyses) do not always provide a reliable estimation of risks and might therefore give an unfair comparison between stent-graft models.

This study also confirms the influence of device-specific factors upon almost all early and late complications. ${ }^{10,13-15,19,26,27}$ The analysis reproduced the widely recognized differences in the incidence of type II endoleak with different stent-graft models. ${ }^{13,26}$ Additionally, differences were also observed in relation to device-related endoleaks between different endografts, some persisting after risk adjustment. Lower incidences of device-related endoleak reflect a combination of maintaining proximal and distal seal and fixation and also better modular stability. Changes in aneurysm diameter remain an important marker of aneurysm exclusion, and device-specific dif- 
ferences have been reported. ${ }^{13,26,28,29}$ Certain stent-graft makes (e.g., Zenith) are associated with shrinkage more than others. The persistence of differences after risk adjustment (e.g., for endoleak) in this study might suggest an additional role for device components, such as fabric, in influencing postoperative changes in aneurysm size. It is also reassuring to note that most of the newer stent-grafts fare better in this respect compared to earlier generation devices.

Kink resistance and fixation depend upon structural aspects of a device, and differences in performance can be expected among stentgrafts. The value of hooks and barbs in improving fixation has been recognized, ${ }^{10}$ which is reflected in this study by the lower risk of migration with devices that incorporate these appendages. Devices without hooks or barbs depend upon columnar strength for fixation. However, a risk of cephalad migration (with or without endoleak) exists if the aneurysm decreases in size. Partially supported devices, such as EVT/Ancure, have the potential to migrate downward only. Differences in applicability of stent-grafts exist due to different fixation methods, which are reflected by differences in patient characteristics (anatomical and general) among the stent-graft labels. Differences in outcome remain even after adjusting for these factors.

Primarily unsupported devices (EVT/Ancure) might be expected to have the highest incidence of stent-graft limb occlusion 13,16,28 because the lack of device support predisposes to angulation and kinking, with resulting stenosis and thrombosis in the graft. ${ }^{32}$ In contrast, this analysis showed that they in fact fared slightly better than the other firstgeneration endografts. This could be due to the smaller number of patients with an Ancure stent-graft. However, this finding might also point to the fact that kink resistance may not be afforded by the mere presence of a stent-graft skeleton but is more a function of the construction of the skeleton.

A high rate of conversion to open repair was found in patients with an EVT/Ancure device. This was primarily due to the large number of conversions for endoleak (including hook breakage) in the early experience with this stent-graft, and this observation is not ap- plicable to the later Ancure device. Significantly fewer conversions were performed in patients with a Zenith device. Zenith also performed better regarding ruptures, as did the AneuRx device. No ruptures were reported with EVT/Ancure, but this might be due to the high number of conversions performed in this group. On the other hand, all-cause mortality, as well as the combined risk of rupture and death or rupture, conversion, and death, was significantly lower with the Excluder endograft. Although the EUROSTAR cohort remains one of the largest, with 56 reported ruptures, caution is necessary while drawing conclusions since the number of ruptures per device label remains small. Encouraging is the observation that 41 ruptures occurred with devices now regarded as obsolete (Stentor, Vanguard, and AneuRx).

\section{Study Limitations}

Despite the strengths of EUROSTAR analyses (i.e., large number of patients, multiple stent-graft makes, and extensive follow-up), there are some limitations to the study. Limited data monitoring and the absence of a core laboratory mean that it is not possible to ascertain adherence to the reporting standards by the large number of centers that contribute to the registry. The effect of this is quenched by regression to the mean. Incompleteness of data is considered inevitable in a voluntary registry; however, significant effort is made to remedy this situation. Incompleteness of follow-up is not expected to have significantly influenced this analysis since it was distributed over the different groups. At the inception, the registry was primed by retrospective registration of baseline information and early follow-up results for $13 \%$ of all currently registered patients. From 1996 onward, when prospective patient registration and data collection was made mandatory, all information relating to these patients was collected prospectively. Retrospective data was mostly of patients with a Stentor device; the influence of this fact upon the analysis is not measurable but is considered negligible.

Despite extensive risk adjustment, it was not possible to correct for every factor that changed during the study period. Manufac- 
turers have incorporated modifications in device features to individual stent-graft labels. Suitability criteria for patients have changed. Also, reporting standards and diagnostic abilities for endoleaks and other complications have evolved. These factors could not be separately adjusted for in the analyses. A combined effect of these and possibly other factors is partly reflected by year of operation, explaining the considerable shifts in risks it brought about. However, these factors might still have had some influence on the results in a way that is not quantifiable

Vanguard, the largest group of the first and second-generation devices, was taken as a control group to evaluate whether enhancements in design features of the other stentgraft labels indeed translated to improvement in outcome. The short and midterm results of the third-generation stent-grafts appear better compared to the early (and now withdrawn) stent-grafts after accounting for the differences in the duration of follow-up. Nevertheless, third-generation stent-grafts are not immune to complications. A complete comparison will not be possible until even longer follow-up becomes available with the third-generation devices.

\section{Conclusions}

Stent-graft labels differ significantly in terms of applicability and individual complications during intermediate and long-term follow-up periods. The differences in outcome are persistent after adjustment for important factors, such as patient characteristics, vascular morphology, and operator experience. Although no single make of stent-graft emerges as the best, it is reassuring to note that the later models of stent-grafts perform better than the early versions. However, so far, reduced risk regarding the primary goal of the intervention-to prevent rupture and death-was observed only for patients with the Excluder device. Results of this comparative analysis should be used to pursue a single device that combines all perceived improvements. Notably, patent protection of some of these design features might be regarded as conflicting with the best interests of our patients.
Acknowledgments: We are indebted to Mrs. M. Kolster for her significant contribution to data management and to others who helped in data management.

\section{APPENDIX}

EUROSTAR participants who contributed patient data to this study:

Austria: University Hospital, Vienna.

Belgium: ASZ and Onze Lieve Vrouwe Hospital, Aalst; AZ Middelheim, St. Vincentius Hospital, UIA, Monica Hospital/OLV/Eeuwfeestkliniek, and St. Augustinus Hospital, Antwerpen; AZ St. Lucas/St. Jozef, Assebroek; Hospital Princesse Paola, Aye; Imelda Hospital, Bonheiden; AZ Klina, Brasschaat; AZ St. Jan AV, Brugge; Hospital Erasme, Academic Hospital VUB, Clinique de l'Europe St. Michel, $\mathrm{CHU}$ Brugmann, and University Hospital St. Luc, Brussels; CHU, Charleroi; AZ St. Blasius, Dendermonde; AZ St. Maarten, Duffel; AZ St. Dimpna, Geel; St. Jan Hospital, AZ St. Lucas, and University Hospital, Genk; St. Joseph Hospital, Gilly; Virga Jesse Hospital, Hasselt; St. Elisabeth, Herenthals; CAZ St. Franciskus Hospital, Heusden-Zolder; AZ Groenige, Kortrijk; University Hospital and Heilig Hart, Leuven; Notre-Dame des Bruyeres, Liège-Chenee; Maria Hospital, Lommel; OLV Hospital, Mechelen; CHM CNDT, Moucron; CHRN, Namur; AZ Heilige Familie, Reet; Stedelijk Hospital and HHR Hart Hospital, Roeselare; St. Trudo Hospital, St. Truiden; St. Josef Hospital, Turnhout; St. Augustinus Hospital, Veurne; St, Josef Hospital, Vilvoorde.

Denmark: Rigshospitalet, Copenhagen; University Hospital, Odense.

France: Hospital Notre Dame, Draguignan; Clinique Mutaliste des Eaux Claires, Grenoble; Hospital for Cardiology, Lille; Hospital Jeanne d'Arc and Hospital E Herriot, Lyon; Polyclinic d'Essey, Nancy; Hospital de la Defense, Nanterre; Hospital Henri Mondor and Hospital Broussais, Paris; CHU Hospital North, St. Etienne; Institut Arnauld Tzanck, St. Laurant du Var; Hospital Sarrus Teinturier and Hospital de Rangueil, Toulouse.

Germany: Surgical University Clinic, Bonn; Augusta Hospital, Düsseldorf; Städtischen Kliniken and Sankt Katharinen, Frankfurt; University Hospital, Freiburg; Altona General Hospital, Hamburg; Henriettenstiftung, Han- 
nover; Klinikum Kempten; Bundeswehrzentral, Koblenz; Park-Krankenhaus, Leipzig; University Hospital, Mainz; Philipps-University, Marburg; Kliniken Rechts der Isar, München; Pius Hospital, Oldenburg; University Hospital, UIm.

Greece: University Medical School, Athens. Ireland: St. James Hospital, Dublin.

Israel: Sheba Medical Centre, Tel Aviv.

Italy: Policlinico Monteluce, Perugia; Ospedale S Giovanni, Rome.

Luxembourg: Centre Hospitalier, Luxembourg.

Monaco: Centre Cardio-Thoracique, Monaco.

The Netherlands: Medical Centre, Alkmaar; Academic Medical Centre, VU, and Onze Lieve Vrouwe Gasthuis, Amsterdam; Gelre Hospital, Apeldoorn; Rijnstate, Arnhem; Reinier de Graaf Group, Delft; Medical Centre Haaglanden Westeinde and Leijenburg Hospital, The Hague; Albert Schweitzer Hospital, Dordrecht; Catharina Hospital, Eindhoven; Medisch Spectrum Twente, Enschede; St. Anna Hospital, Geldrop; Academic Hospital and Martini Hospital, Groningen; Academic Hospital, Maastricht; St. Antonius Hospital, Nieuwegein; CWZ Hospital and Academic Hospital, Nijmegen; St. Clara Hospital, Dijkzicht Hospital, and Franciscus Gasthuis, Rotterdam; Elisabeth Hospital and Tweesteden Hospital, Tilburg; University Medical Centre, Utrecht; St. Josef Hospital, Veldhoven; Isala Clinics Sophia, Zwolle.

Norway: Aker University Hospital and UIleval Hospital, Oslo; University Hospital, Trondheim.

Poland: L'Academie de Medicine, Lublin; Medical University, MSWiA Hospital, and Central Military Hospital, Warsaw.

Spain: University Hospital, Ciutat Sanitaria i Universitaria de Bellvitge, and Hospital de la Santa Creu i Sant Pau, Barcelona; Hospital de Gipuzkoa, Donostia San Sebastian; Hospital Juan Canalejo and Hospital Santa Teresa, La Coruña; Hospital de Leon, Hospital Xeral Lugo, University Hospital de la Princesa, Hospital Ramon y Cajal, Fundacion Jimenez Diaz, and University Hospital of Getafe, Madrid; University Hospital of Navarra, Pamplona; Hospital Clinico, Valladolid.
Sweden: University Hospital, Lund; Medical Centre, Örebro.

Switzerland: Clinic for Cardiovascular Surgery, Bern; Gefässzentrum, Zürich.

Turkey: Memorial Hospital and University Hospital, Istanbul.

United Kingdom: Royal Hospital, Bournemouth; Royal Infirmary, Bristol; Countess of Chester Hospital, Chester; Gartnavel Hospital, Glasgow; Royal Infirmary, Hull; Royal University Hospital, Liverpool; St. Mary's Hospital, London; Withington Hospital, Manchester; Freeman Hospital, Newcastle Upon Tyne.

\section{REFERENCES}

1. Parodi JC, Palmaz JC, Barone HD. Transfemoral intraluminal graft implantation for abdominal aortic aneurysms. Ann Vasc Surg. 1991;5: 491-499.

2. Chuter TA, Green RM, Ouriel K, et al. Transfemoral endovascular aortic graft placement. $J$ Vasc Surg. 1993;18:185-197.

3. Becquemin JP, Bourriez A, d'Audiffret $A$, et al. Mid-term results of endovascular versus open repair of abdominal aortic aneurysm in patients anatomically suitable for endovascular repair. Eur J Vasc Endovasc Surg. 2000;19:656661.

4. Zarins CK, White RA, Schwarten D, et al. AneuRx stent graft versus open surgical repair of abdominal aortic aneurysms: multicenter prospective clinical trial. J Vasc Surg. 1999;29: 292-308.

5. Bush RL, Najibi S, Lin PH, et al. Early experience with the bifurcated Excluder endoprosthesis for treatment of the abdominal aortic aneurysm. J Vasc Surg. 2001;33:497-502.

6. Criado FJ, Wilson EP, Fairman RM, et al. Update on the Talent aortic stent-graft: a preliminary report from United States phase I and II trials. J Vasc Surg. 2001;33:S146-149.

7. Greenberg RK, Lawrence-Brown M, Bhandari $G$, et al. An update of the Zenith endovascular graft for abdominal aortic aneurysms: initial implantation and mid-term follow-up data. $J$ Vasc Surg. 2001;33:S157-164.

8. Moore WS, Rutherford RB. Transfemoral endovascular repair of abdominal aortic aneurysm: results of the North American EVT phase 1 trial. J Vasc Surg. 1996;23:543-553.

9. Mialhe C, Amicabile C, Becquemin JP. Endovascular treatment of infrarenal abdominal aor- 
tic aneurysms by the Stentor system: preliminary results of 79 cases. J Vasc Surg. 1997;26: 199-209.

10. Ahn SS, Ro KM. An overview of the currently available endovascular devices for AAA repair. In: Branchereau A, Jacobs M, eds. Surgical and Endovascular Treatment of Aortic Aneurysms. Armonk, NY: Futura Publishing Company, Inc.; 2000:81-89.

11. May J, White GH, Yu W, et al. Endoluminal repair of abdominal aortic aneurysms: strengths and weaknesses of various prostheses observed in a 4.5-year experience. $J$ Endovasc Surg. 1997;4:147-151.

12. Resch T, Malina M, Lindblad B, et al. The impact of stent-graft development on outcome of AAA repair-a 7-year experience. Eur J Vasc Endovasc Surg. 2001;22:57-61.

13. Ouriel K, Clair DG, Greenberg RK, et al. Endovascular repair of abdominal aortic aneurysms: device-specific outcome. J Vasc Surg. 2003;37: 991-998.

14. Greenberg RK, Deaton D, Sullivan T, et al. Variable sac behavior after endovascular repair of abdominal aortic aneurysm: analysis of core laboratory data. J Vasc Surg. 2004;39:95-101.

15. Sternbergh WC, Conners MS, Tonnessen BH, et al. Aortic aneurysm sac shrinkage after endovascular repair is device-dependent: a comparison of Zenith and AneuRx endografts. Ann Vasc Surg. 2003;17:49-53.

16. Carroccio A, Faries PL, Morrissey NJ, et al. Predicting iliac limb occlusions after bifurcated aortic stent grafting: anatomic and devicerelated causes. J Vasc Surg. 2002;36:679-684.

17. Rutherford RB. Reply on: Regarding 'Problems with the dissemination of up-to-date information on the results of endograft repair for abdominal aortic aneurysm' (Letter). J Vasc Surg. 1999;30:768-769.

18. Harris $\mathrm{PL}$, Buth J, Mialhe $\mathrm{C}$, et al. The need for clinical trials of endovascular stent-graft techniques for abdominal aortic aneurysm repair: the EUROSTAR project. J Endovasc Surg. 1997; 4:72-77.

19. Buth J, Laheij RJF, on behalf of the EUROSTAR Collaborators. Early complications and endoleaks after endovascular abdominal aortic aneurysm repair: report of a multicenter study. $J$ Vasc Surg. 2000;31:134-147.

20. Moore WS, for the EVT Investigators. The EVT tube and bifurcated endograft systems: tech- nical considerations and clinical summary. $J$ Endovasc Surg. 1997;4:182-194.

21. Umscheid T, Stelter WJ. Time-related alterations of shape, position, and structure in selfexpanding modular aortic stent-grafts. J Endovasc Surg. 1999;6:17-32.

22. Zarins CK, White RA, Moll FL, et al. The AneuRx stent graft: four-year results and worldwide experience 2000. J Vasc Surg. 2001; 33:S135-145.

23. Faries PL, Brener BJ, Connelly TL, et al. A multicenter experience with the Talent endovascular graft for the treatment of abdominal aortic aneurysms. J Vasc Surg. 2002;35:11231128.

24. Harris P, Brennan J, Martin J, et al. Longitudinal aneurysm shrinkage following endovascular aortic aneurysm repair: a source of intermediate and late complications. J Endovasc Surg. 1999;6:11-16.

25. Leurs LJ, Hobo R, Buth J. The multicenter experience with a third-generation endovascular device for abdominal aortic aneurysm repair. A report from the EUROSTAR database. J Cardiovasc Surg (Torino). 2004;45:293-300.

26. Nevelsteen A, Maleux G. Endovascular abdominal aortic aneurysm treatment: device-specific outcomes. J Cardiovasc Surg (Torino). 2004;45: 307-319.

27. Laheij RJ, van Marrewijk CJ, for the EUROSTAR group. The evolving technique of endovascular stenting of abdominal aortic aneurysm: time for reappraisal. Eur $J$ Vasc Endovasc Surg. 2001;22:436-442.

28. Bertges DJ, Chow K, Wyers MC, et al. Abdominal aortic aneurysm size regression after endovascular repair is endograft dependent. $J$ Vasc Surg. 2003;37:716-723.

29. Rhee RY, Eskandari MK, Zajko AB, et al. Longterm fate of the aneurysmal sac after endoluminal exclusion of abdominal aortic aneurysms. J Vasc Surg. 2000;32:689-696.

30. Cho JS, Dillavou ED, Rhee RY, et al. Late abdominal aortic aneurysm enlargement after endovascular repair with the Excluder device. $J$ Vasc Surg. 2004;39:1236-1242.

31. Laheij RJ, van Marrewijk CJ, Buth J, et al. The influence of team experience on outcomes of endovascular stenting of abdominal aortic aneurysms. Eur J Vasc Endovasc Surg. 2002;24: 128-133.

32. Baum RA, Stavropoulos SW, Fairman RM, et al. Endoleaks after endovascular repair of abdominal aortic aneurysms. J Vasc Interv Radiol. 2003;14:1111-1117. 